\title{
A study on the relationship between Life Satisfaction and Materialism
}

\author{
Jasmi M. Patel ${ }^{1}$, Vidyadayani Shetty ${ }^{2}$ \\ ${ }^{1}$ Student, Department of Psychology, Nagindas Khandwala College, Mumbai. \\ ${ }^{2}$ Associate Professor, Department of Psychology, Nagindas Khandwala College, Mumbai. \\ Corresponding Author: Vidyadayini Shetty \\ Email: vidhi33@gmail.com
}

\begin{abstract}
Background: Materialism is defined as the importance a consumer accords to worldly possessions. At the highest level of materialism, such possessions assume a central place in a person's life and are believed to provide the greatest sources of satisfaction and dissatisfaction. Satisfaction with one's life implies a contentment with or acceptance of one's life circumstances, or the fulfilment of one's wants and needs for one's life as a whole. In essence, life satisfaction is a subjective assessment of the quality of one's life. Because it is inherently an evaluation, judgements of life satisfaction have a large cognitive component. The present study explores the relationship between materialism and life satisfaction in young adults.

Methodology: The scales were compiled together and administered to a representative sample of 60 participants from the age range of 18-25 years. The two scales used were Material Value Scale and The Satisfaction with Life Scale. The data was analysed using the $t$ test and correlational coefficient.

Result: There is no significant relationship between materialism and life satisfaction $(r=0.079)$. Only happiness indicated a weak significantly negatively correlation with life satisfaction $(-0.261)$. The $t$ values of both variables indicate that there is no significant difference between scores of materialism and life satisfaction for males and females.
\end{abstract}

Conclusion: The results indicate that materialism and life satisfaction had no significant correlation, and there is no significant gender difference between the score of materialism and life satisfaction.

Keywords: Materialism, Life satisfaction, Gender, Adolescents.

(Paper received $-22^{\text {nd }}$ April 2020, Peer review completed $-26^{\text {th }}$ May 2020)

(Accepted $-28^{\text {th }}$ May 2020)

\section{INTRODUCTION}

Simple living and high thinking goes the proverb. We are greatly influenced by the teachings of Gautama Buddha, Mahatma Gandhi, Dr Abdul Kalam, and many more great personalities who advocated frugal living and high thinking. According to Maslow's hierarchy of needs theory of motivation, all these great personalities are self-actualized individuals who have realized their potentials to the maximum level, were happy and satisfied with their life. Since ages, Indian culture has inculcated the concept of looking inside for happiness, rather than looking at external sources. However, with the advent of globalization, liberalization and the internet, youngsters crave to possess status symbols and hoard materialistic things to advertise their happiness and bliss. Belk defines materialism as the importance a consumer accords to worldly possessions. At the highest level of materialism, such possessions assume a central place in a person's life and are believed to provide the greatest sources of satisfaction and dissatisfaction [1]. Satisfaction is a Latin word that means to make or do enough. Satisfaction with one's life implies a contentment with or acceptance of one's life circumstances, or the fulfilment of one's wants and needs for one's life as a whole. In essence, life satisfaction is a subjective assessment of the quality of one's life. Because it is inherently an evaluation, judgements of life satisfaction have a large cognitive component [2]. The Satisfaction with life scale was developed to assess 
satisfaction with people's lives as a whole. The scale does not assess satisfaction with specific life domains, such as health or fiancés, but allows subjects to integrate and weigh these domains in whatever way they choose [3]. A past research was conducted to validate the MVS scale and to explore the relationships between material values and subjective well-being of Croatian citizens. The results indicated that people who believed that the material goods in one's life lead to happiness reported to have lower life satisfaction, lower level of positive affect and higher level of negative affect over the past month. The centrality dimension was positively related to positive affect, indicating that the belief that possessions play a central role in enjoyment leads to more frequent experiences of happiness and satisfaction over the past month [4]. The purpose of the study was to explore the relationship between materialism and life satisfaction in adolescents. Hypotheses for the current study were -

- There will be no significant relationship between materialism and life satisfaction.

- There will be no significant gender differences in the scores of materialism and life satisfaction.

\section{METHODOLOGY}

A convenience sample of 60 participants was recruited through WhatsApp and by email. All the 60 participants were the citizens of Mumbai city. The sample ranged from 18 to 25 years of age. The sample consisted of 30 male and 30 female participants. No ethical concerns were identified in the design of the study, other than ensuring it was only participated in by consenting adults between the ages of 18-25 years who were fluent in English language. It was also ensured that the participants were not from psychology background. A google form was made which described the purpose of the research contained questionnaire of both the scales. It was sent to individuals through WhatsApp or email and the participants were asked to further forward the link of the google form to their friends as well. Thus, snowball technique was used. A consent form was attached at the start of the survey. In all 75 responses were collected but 15 were discarded as their age did not fall into decided age range for the research (i.e.18-25yrs). The following scales were used to measure materialism and life satisfaction:

1. Material Value Scale - The 9-item short version form of material value scale was used in the current study to assess participant's level of materialism. The participants had to answer how much they agree or disagree with the statements on a five-point Likert scales which ranged from 1 as "strongly disagree" to 5 as "strongly agree' [5] The scale consists of three dimensions: The first factor (labelled success) represents the use of possessions as an indicator of success in life, which corresponds to the third domain of materialism described in the literature review. The second factor (centrality) concerns the importance of acquisition and possession generally, and the third (happiness) concerns the perception that possessions are needed for happiness [6]. The three subscales scores as well as overall materialism scores were calculated. All the items were interpreted such that a higher score means more materialism. The validity and reliability for index for nine item version $=0.36$.

2. The Satisfaction with Life Scale - The SWLS is a 7-point Likert style response scale. The possible range of scores is 5-35, with a score of 20 representing a neutral point on the scale. The coefficient alpha for the scale has ranged from 0.79 to 0.89 , indicating that the scale has high internal consistency. The scale was also found to have good test-retest correlations $(0.84,0.8$ over a month interval) [3]

\section{RESULTS AND DISCUSSION}

Table 1: Correlation between various dimensions of materialism and life satisfaction scores

\begin{tabular}{|l|l|l|l|l|l|}
\hline & Happiness & Success & Centrality & Total MVS & Life Satisfaction \\
\hline Life satisfaction & $-0.261^{*}$ & $0.036^{\mathrm{NS}}$ & $0.039^{\mathrm{NS}}$ & $-0.079^{\mathrm{NS}}$ & 1.000 \\
\hline \multicolumn{7}{|c}{$\mathrm{p}<0.05, \mathrm{NS}-$ not significant }
\end{tabular}


The results were analyzed using MegaStats. Descriptive and inferential statistics was administered based on objectives and hypotheses. The $\mathrm{r}$ value indicates that there was no significant relationship between materialism and life satisfaction $(r=0.079)$. The findings were not consistent with other research findings. A study [7] suggest negative correlation between materialism and life satisfaction. Individuals who were high in materialism were less satisfied in their life 'as a whole' than those who were low in materialism. Also, another study demonstrated people who pursue happiness through material gain tend to feel worse, and this is related to negative appraisals of their satisfaction with life [8]. The cultural differences could be one of the reasons for adolescents not equating materialism with life satisfaction.

Minimalist living or minimalist lifestyle is being accepted and followed by many people these days. A lot of people emphasis on simple living without many possessions. Many religions in India like Buddhism, Hinduism promote the minimalist view. Especially in Jainism there is a concept called as 'Aparigraha' (nonpossession) and is considered as one of the main virtues. Jainism explains that a person should not accumulate possessions and power beyond his bare minimum requirement. Jainism believes that individuals should have possession which fulfills his basic needs. Possession means person deny and deprive others right to possess which another person requires. The best advice is person should give up his sense of 'mineness'. Possession of material things would bring unlimited anxiety, surrender to immoral activities, to do injustice and take shelter in falsehood. Parigraha (possession) is the cause of all problems. It takes away peace, makes man devil and encourages doing all sorts of wrong things. It is the root cause in terms of finance and creates all types of imbalances in society [9].

The three dimensions of the materialism scale were correlated with life satisfaction. The correlation indicated that happiness, one of the dimensions of MVS, was negatively correlated with life satisfaction $(\mathrm{r}=$ - 0.261). In the scale used happiness is described as owning possessions which individuals believe will enhance their well-being. The results indicated that there is a significant low, negative relationship between the factor 'Happiness' and life satisfaction. Thus, the results suggested that all those people who felt that material goods were important to make oneself happy were less satisfied in their life. Happiness and materialism are somewhat mutually exclusive, one cannot get both at the same time. One has to get rid of their material tendencies sooner or later in order to be happy and content. According to the past research it was found out that individuals high in gratitude showed less of a relationship between materialism and negative affect. Additionally, individuals high in materialism showed decreased life satisfaction when either gratitude or positive affect was low. Thus, negative affect, positive affect, and gratitude seem to be important variables in the relationship between materialism and dissatisfaction with life [8].

Table 2: Mean and SD of materialism and life satisfaction of male and females

\begin{tabular}{|l|l|c|l|c|}
\hline & Materialism & Life satisfaction \\
\hline & Mean & SD & Mean & SD \\
\hline Males & 24.70 & 6.44 & 24.97 & 6.11 \\
\hline Females & 26.50 & 5.82 & 22.07 & 7.47 \\
\hline t value & 1.14 & -1.65 \\
\hline$p$ value & $0.2608 \mathrm{NS}$ & $0.1053 \mathrm{NS}$ \\
\hline
\end{tabular}

The second hypothesis explored gender difference in the scores of materialism and life satisfaction. The $t$ values of both variables indicate that there is no significant difference between scores of materialism and life satisfaction for males and females. The results are in line with the null hypothesis. This means that both males and females almost weighed equal in these variables and neither of them scored comparatively high or low. A research was conducted to examine gender differences in life satisfaction globally and across demographic groups. The results suggested that gender differences in life satisfaction were found to be significant yet small. Women reported higher levels of life satisfaction than men across all income, education, and employment groups. The direction of gender differences in life satisfaction was inconsistent across age and regional groups. Men scored higher than women only over the age of about 63 , and in subSaharan Africa. Despite the less favourable objective conditions for women globally, women were found to 
be more satisfied with their lives than men across most of the groups [10]. In an another study on materialism it was found that females scored higher on materialism than males which seemed to be based on higher scores on the centrality subscale [11]

Intrinsic goals such as financial success are those that depend on the contingent reaction of others. Further, they are typically engaged in as means to some other end. Conversely, intrinsic goals are likely to satisfy basic and inherent psychological needs. In a study on Intrinsic and Extrinsic goals it was found that the relative importance and efficacy of extrinsic aspirations for financial success, and social recognition were associated with lower vitality and self-actualization and more physical symptoms. Conversely, the relative importance and efficacy of intrinsic aspiration of self-acceptance, affiliation, community feeling, and physical health have associated with higher wellbeing and less distress [12]. Thus, teachers and mental health professional should emphasize on minimalistic lifestyle and intrinsic goals, which would help people choose subjective experience wisely and a small shift could make a difference in their happiness and wellbeing.

\section{CONCLUSION}

The results indicate that materialism and life satisfaction had no significant correlation, and there is no significant gender difference between the score of materialism and life satisfaction.

\section{REFERENCES}

1. Belk RW. Materialism: Trait aspects of living in the material world. J Consumer Res 1985;12(3):265-80.

2. Sousa L, Lyubomirsky S. Life satisfaction. In J. Worell (Ed.), Encyclopedia of women and gender: Sex similarities and differences and the impact of society on gender 2001;2:667-76.

3. Diener E, Emmons RA, Larsen RJ, Griffin S. The Satisfaction with Life Scale. J Personal Assess 1985;49:715.

4. Lipovčan LK, Prizmić-Larsen Z, Brkljačić T. Materialism, affective states, and life satisfaction: case of Croatia. Springer Plus 2015 4:699.

5. Richins M. The Material Values Scale: Measurement Properties and Development of a Short Form. J Consumer Res 2004;31(1):209-19.

6. Richins M, Dawson SA. Consumer Values Orientation for Materialism and Its Measurement. J Consumer Res 1992;19:303-16.

7. Ryan L, Dziurawiec S. Materialism and Its Relationship to Life Satisfaction. Soc Indicators Res 2001;55: 18597.

8. Roberts JA, Tsang JA, Manolis C. Looking for happiness in all the wrong places: The moderating role of gratitude and affect in the materialism-life satisfaction relationship, J Positive Psychol 2015;10(6):489-98.

9. Shah K. The philosophy of welfare economics of DR Amartya Sen and Jain philosophy. Chapter 10- The doctrine of Aparigraha, Effective tool in Jain Philosophy ; 2008.

10. Joshanloo M, Jovanović V. The relationship between gender and life satisfaction: analysis across demographic groups and global regions. Arch Wom Ment Health 2019;1-8.

11. Workman J, Lee S. Materialism, fashion consumers and gender: a cross- cultural study Int J Consumer Stud 2011;35(1):50-7.

12. Kasser T, Ryan R. Further examining the American dream: Differential correlates of Intrinsic and Extrinsic goals. Personal Soc Psychol Bull 1996;22(3):280-7.

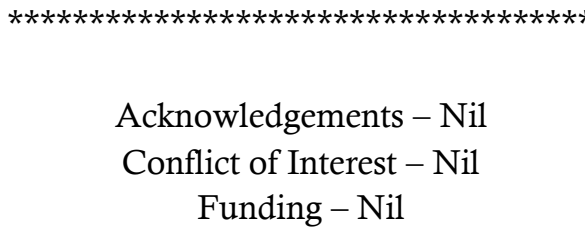

